\author{
Asian Journal of \\ Medical and Biological Research \\ ISSN 2411-4472 (Print) 2412-5571 (Online) \\ www.ebupress.com/journal/ajmbr
}

\title{
Article \\ Knowledge and practices regarding infection control among nurses in secondary level hospital
}

\author{
Ringku Das ${ }^{1}$, Ashees Kumar Saha ${ }^{2}$, Priti Kana Barua ${ }^{3}$, Jay Priya Borua ${ }^{4}$, Nasima Akhter ${ }^{5}$ and Akram Hossain ${ }^{6}$ \\ ${ }^{1}$ Senior Staff Nurse, 250 Bedded General Hospital, Chattogram, Bangladesh \\ ${ }^{2}$ Nursing Officer, Upazila Health Complex, Bagha, Rajshahi, Bangladesh \\ ${ }^{3}$ Nursing Instructor, Fouzderhat Nursing College, Chattogram, Bangladesh \\ ${ }^{4}$ Senior Staff Nurse, 250 Bedded General Hospital, Chattogram, Bangladesh \\ ${ }^{5}$ Nursing Teacher, Bandarban Nursing College, Bandarban, Bangladesh \\ ${ }^{6}$ Professor, NIPSOM, Mohakhali, Dhaka, Bangladesh
}

*Corresponding author: Ringku Das, Senior Staff Nurse, 250 Bedded General Hospital, Chattogram, Bangladesh. Phone: +8801703754594; E-mail: ringkudas188@gmail.com

Received: 21 November 2020/Accepted: 27 December 2020/ Published: 31 December 2020

\begin{abstract}
Infection control and standard precautions is evidence-based practices that can reduce the risk of transmission of microorganisms. Infection control education is a fundamental component of the Nursing curriculum. A cross-sectional study was conducted to assess the level of knowledge and practices regarding infection control among nurses in secondary level hospital at 250 beds Chittagong General Hospital and Fouzderhat TB Hospital, Chittagong. The study period was $1^{\text {st }}$ January to $31^{\text {st }}$ December 2018 . Total 182 nurses were included in this study. The respondents were selected by purposive sampling technique and data were collected by face to face interview. The study was found that (78.0\%) respondents had fair knowledge and (90.2\%) had fair practices regarding infection control. The study also revealed that, $161(88.5 \%)$ respondents awarded about hand washing, 179 (98.4\%) respondents were concerned about waste management and 93 (51.1\%) respondents agree and 85 (46.7\%) respondents strongly agree about PPE use is important. Significant statistical difference was found between working experience and knowledge level. This study can be concluded that in spite of practice level regarding infection control, nurses had fair knowledge level. These finding suggest that nurse knowledge and practice regarding infection control need further improvement.
\end{abstract}

Keywords: infection; infection control; knowledge; practice; standard precautions; personal protective equipment

\footnotetext{
1. Introduction

A nurse can play an important role in controlling hospital infections via updated knowledge, enhanced attitude and professional behaviors (Angelillo et al., 1999). The nurses have a key role to ensure that infection control procedure and practice in order to prevent patients from acquiring an infection and to protect health care staff from health care-associated infection (HCAI). It is well documented by the world health organization and other international health groups that health care- associated infection (HCAI) in developing countries is a major for patient safety. Nursing staff often have limited knowledge and training of infection control practices in their implementation during daily patient care. Poor knowledge has been associated with poor attitude and poor practices of infection control in hospital settings.

Infection prevention and control is very essential in hospital setting to reduce morbidity and mortality of the patients. It has been estimated that one out of every 20 hospitalized patients will contract a healthcare-associated infection (Vaidya, 2013).
} 
Infection prevention and control efforts have historically focused on monitoring and preventing HAIs locally; however, HAI prevention has recently become a global priority, which has resulted in an evolution of infection prevention and control (Yokoe, 2008). Healthcare acquired infections (HCAIs) otherwise call nosocomial infection is associated with increased morbidity and mortality among hospitalized patients and predisposes healthcare workers (HCWs) to an increased risk of infections (Garba et al., 2015).

Nurses can prevent infection transferring among the patients of a hospital with proper disinfecting the skin, wearing gloves and masks, changing infusion sets, applying prudential measures, proper isolation, using the principles of standard cautions, observing hand hygiene, preventing accidental contact of hand with needle-stick and avoiding the infected respiratory discharges. However, the results of the current study suggested that the majority of units under study had inadequate knowledge about controlling hospital infections. Nurses' knowledge about hospital infection prevention and control is reported differently and sometimes paradoxically. In McBride study in America, most of the nurses (65\%) had no proper knowledge about controlling hospital infections (McBride, 1994).

Therefore, in order to establish a proper behavior by proper performance of nurses and other members of the treatment team concerning hospital infection control and prevention, it is necessary to provide departments with conditions and facilitation for appropriate performance; for example, adequate human resources, suitable equipment, permanent and updated education etc., and then according to the World Health Organization recommendation, the behaviors should be monitored through continuous observation (Sax et al., 2009).

In Bangladesh, health-care facilities have deficiencies in their structural design, which include the lack of sufficient sinks, bedside hand-rub dispensers and patient isolation facilities. Management of hospital waste is another neglected area. The indiscriminant use of antibiotics also contributes to very high infections in developing countries other factors such as the lack of awareness of infection control problems, and individual behavior can impede the prevention of hospital-acquired infections. Nosocomial infections increase the costs of healthcare due to added antimicrobial treatment and prolonged hospitalization. Since the prevalence of nosocomial infections is generally higher in developing countries with limited resources, the socio-economic burden is even more severe in these countries. This review summarizes the current knowledge on the risks of HAI and summarizes current recommendations for the development of hospital infrastructure and the institution of protocols to reduce HAIs in LMICs such as Bangladesh.

Therefore this cross sectional study has undertaken among nurses with the objective to assess the level of knowledge and practices regarding infection control among nurses in secondary level hospitals.

\section{Materials and Methods}

\subsection{Ethical implication}

All types of ethical clearance were obtained from the ethical committee of NIPSOM.

\subsection{Study design}

A cross sectional study design was adopted for this study.

\subsection{Study period}

This study was conducted from $1^{\text {st }}$ January 2018 to $31^{\text {st }}$ December 2018.

\subsection{Study population}

For this study, nurses who work in mentioned different level of health facilities.

a) Study place: Chittagong General Hospital and Fouzderhat TB Hospital, Chittagong.

b) Sampling technique: Purposive sampling technique was done. Sample size 182

c) Inclusion criteria:

- Nurses who are in-service.

- Nurses who will be willing to participate in the study.

d) Exclusion criteria:

- Unwilling to participate in the study.

- Nurses who are physical and mentally sick

- Nurses who are earn leave, maternity leave during the study.

e) Tool of the study: The semi structured questionnaire was developing in English and Bengali. The questionnaire was developed using selected variables according to the specific objectives of the study and simple, easily understandable to the respondents. A Likert scale was chosen as the method to elicit 
respondents responses because it is easy to understand and relatively simple for respondents to rank their opinion on a continuum of responses.

Knowledge was assessed by a set of 08 questions. For every correct response, 1 point was given and 0 was given for an incorrect answer. Consequently, knowledge scores ranged from 0 to 08 . The knowledge scores were classified into poor knowledge $(<50 \%)$, Fair knowledge $(51-80 \%)$ and good knowledge $(>80 \%)$.

Practice was assessed by 08 statement using a 5-item Likert scale (ranging from strongly agree $=5$ to strongly disagree $=1)$. The practice scores were categorized into good $(>80 \%)$, Fair $(59-79 \%)$ and poor $(<59 \%)$.

\subsection{Pre-testing}

Pretest was done among 20 nurses from the same group or characteristic of study population in "Chittagong Medical College \& Hospital" to check the accuracy and degree of reliability of the questionnaire. The questionnaire was finalized on the basis of present findings and reviewed by guide. All data will be analyzed by using the statistical package for social sciences (SPSS) software version 22. To assess the objective statistics mean, median, mode, range \& standard deviation for numerical data frequency \& percentage were used. To find out statistical association chi square tests were done. $\mathrm{P}$ value $(\mathrm{p}<0.05)$ was considered to be statistically significant.

\section{Results and Discussion}

The study was conducted to assess the knowledge and practices regarding infection control among nurses in secondary level hospitals on 250 bed Chittagong general hospital and Fouzderhat TB hospital, Chittagong.

Table 1. Demographic characteristics of the respondents $(n=182)$.

\begin{tabular}{|c|c|c|}
\hline Age (in years) & Frequency & Percent \\
\hline 30 to 34 & 33 & 18.13 \\
\hline 35 to 39 & 13 & 7.14 \\
\hline 40 to 44 & 47 & 25.82 \\
\hline 45 and above & 89 & 48.90 \\
\hline \multicolumn{3}{|l|}{ Gender } \\
\hline Female & 173 & 95 \\
\hline Male & 9 & 4.9 \\
\hline \multicolumn{3}{|l|}{ Level of Education } \\
\hline diploma in nursing & 116 & 63 \\
\hline BSc in nursing & 52 & 28.6 \\
\hline Master's degree in nursing science / public health & 14 & 7.7 \\
\hline \multicolumn{3}{|l|}{ Current position } \\
\hline Staff nurse & 34 & 18.7 \\
\hline Senior staff nurse & 143 & 78.6 \\
\hline Nursing supervisor & 04 & 2.2 \\
\hline others & 01 & 0.5 \\
\hline \multicolumn{3}{|l|}{ Shift of the respondents } \\
\hline Morning & 132 & 72.5 \\
\hline Evening & 50 & 27.5 \\
\hline Night & 0 & \\
\hline \multicolumn{3}{|l|}{ Place of the respondents } \\
\hline Emergency & 11 & 6.0 \\
\hline Surgery & 29 & 15.9 \\
\hline Gynae & 32 & 17.6 \\
\hline Post-operative & 13 & 7.1 \\
\hline others & 97 & 53.3 \\
\hline \multicolumn{3}{|l|}{ Working Experience } \\
\hline $1-5$ years & 24 & 13.2 \\
\hline 6-10years & 13 & 7.1 \\
\hline 10-15years above & 54 & 29.7 \\
\hline 15 years above & 91 & 50.0 \\
\hline \multicolumn{3}{|l|}{ Regular training } \\
\hline Yes & 164 & 90.1 \\
\hline
\end{tabular}




\begin{tabular}{|l|l|l|}
\hline No & 18 & 9.9 \\
\hline Regular infection control training & & \\
\hline Yes & 57 & 31.3 \\
\hline No & 126 & 68.7 \\
\hline
\end{tabular}

Table 1 shows that majority of the respondents were 45 and above $89(48.90 \%)$ were from 40 to 44 years 47 (25.82\%) and 30 to 34 years $33(18.13 \%)$ were from below 35 to 39 years $13(7.14 \%)$. The mean age of the respondents was 43.37 with $\mathrm{SD}=6.552$ including $173(95 \%)$ were female and rests were male $9(4.9 \%)$. Majority of the respondents $116(63 \%)$ were completed diploma in nursing and midwifery, $52(28.6 \%)$ BSc in nursing and few of them 14 (7.7\%) were completed master's degree in nursing science / public health. Among them, majority of the respondents 143 (78.6\%) were from senior staff nurse, $34(18.7 \%)$ respondents staff nurse and nursing supervisor $04(2.2 \%)$ and others $01(.5 \%)$, from them majority of the respondents duty $132(72.5 \%)$ morning duty and evening duty $50(27.5 \%)$. Out of 182 respondents, $13(7,1 \%)$ were working place in Emergency ward, $11(6.0 \%)$ in postoperative, 29 (15.9\%) in Surgery, $32(17.6 \%)$ in Gynae ward and rest of them $97(53.3 \%)$ work in others ward and their working experience were (50.0\%) 15 years above. Majority of the respondents 164 (90.1\%) infection control training received and some respondents 18 (9.9\%) were not received. Regular infection control training was not received 126 (68.7\%) and received 57 (31.3\%).

Table 2. Distribution of the respondents by knowledge regarding infection control (n-182).

\begin{tabular}{|c|c|c|}
\hline Know about Infection & Frequency & Percent \\
\hline Yes & 182 & 100 \\
\hline No & 00 & 00 \\
\hline \multicolumn{3}{|c|}{ Know about Infection control } \\
\hline Yes & 182 & 100 \\
\hline No & 00 & 00 \\
\hline \multicolumn{3}{|c|}{ Know about Infectious diseases } \\
\hline Yes & 173 & 96.1 \\
\hline No & 9 & 3.9 \\
\hline \multicolumn{3}{|c|}{ Infection control training duration } \\
\hline Yes $(1-7)$ & 164 & 90.7 \\
\hline No & 18 & 9.3 \\
\hline \multicolumn{3}{|c|}{ Know about Infection control policies } \\
\hline Yes & 163 & 89.6 \\
\hline No & 18 & 10.4 \\
\hline \multicolumn{3}{|c|}{ Know about Infection control committee } \\
\hline Yes & 162 & 89.1 \\
\hline No & 20 & 10.9 \\
\hline \multicolumn{3}{|c|}{ Know about Infection control team } \\
\hline Yes & 162 & 89.1 \\
\hline No & 20 & 10.9 \\
\hline \multicolumn{3}{|c|}{ Know about Vaccination schedule } \\
\hline \multicolumn{3}{|l|}{ Yes } \\
\hline No & 35 & 19.2 \\
\hline Total & 182 & 100.00 \\
\hline
\end{tabular}


Table 2 shows that all the respondents (100\%) knew about Infection and Infection Control, almost 173 (96.1\%) knew about infectious diseases. Majority of the respondents had 1-7 days duration infection control training. $164(90.7 \%)$ and few respondents were no infection control training. Here, 163 (89.6\%) respondents knew about Infection Control policies, $162(89.1 \%)$ respondents knew about Infection Control committee and team and, $147(80.8 \%)$ knew about vaccination schedule.

Table 3. Respondents by their knowledge about infection control $(n=182)$.

The knowledge scores were classified into Poor knowledge $(<50 \%)$, Fair knowledge $(51-80 \%)$ and Good knowledge $(>80 \%)$.

\begin{tabular}{|l|l|l|}
\hline Knowledge assessment score & Frequency & Percent \\
\hline Poor & 9 & 4.9 \\
\hline Fair & 142 & 78.0 \\
\hline Good & 31 & 17.01 \\
\hline Total & 182 & 100.0 \\
\hline
\end{tabular}

Table 3 shows that majority of the respondents (78.0\%) had fair knowledge about infection control, whereas $(17.01 \%)$ good knowledge and poor knowledge had (4.9\%).

Table 4. Distribution of the respondents by hand washing matter $(n=182)$.

\begin{tabular}{|l|l|l|}
\hline Hand washing matter & Frequency & Percentage \\
\hline Awarded about hand washing & 161 & 88.5 \\
\hline Yes & 21 & 11.5 \\
\hline No & & \\
\hline Hand washing training & 177 & 97.3 \\
\hline Yes & 05 & 2.7 \\
\hline No & \multicolumn{2}{l|}{} \\
\hline Hand washing step (six steps) & 27 & 14.8 \\
\hline Yes & 155 & 85.2 \\
\hline No & 182 & 100.00 \\
\hline Total & \multicolumn{2}{l}{} \\
\hline
\end{tabular}

Table 4 show majority of the respondents 161 (88.5\%) awarded about hand washing and few $21(11.5 \%)$ were not awarded. Most of the respondents 177 (97.3\%) received hand washing training and few $5(2.7 \%)$ were not received. Among them $27(14.8 \%)$ respondents had maintained six steps hand washing technique and $155(85.2 \%)$ were not maintained.

Table 5. Distribution of the respondents by concerned of waste and waste management $(n=182)$.

\begin{tabular}{|l|l|l|}
\hline Concerned about waste & Frequency & Percentage \\
\hline Yes & 179 & 98.4 \\
\hline No & 03 & 1.6 \\
\hline Concerned about waste management & \multicolumn{2}{|l|}{} \\
\hline Yes & 175 & 96.2 \\
\hline No & 07 & 3.8 \\
\hline Concerned about biomedical waste management & 71 & 39.0 \\
\hline Yes & 111 & 61.0 \\
\hline No & 164 & 90.1 \\
\hline Disposed sharp waste in red bin & 17 & 8.9 \\
\hline Yes & $\mathbf{1 8 2}$ & $\mathbf{1 0 0 . 0}$ \\
\hline No &
\end{tabular}

Table 5 shows that majority of the respondents 179 (98.4\%) were concerned about waste management and few respondents $3(1.6 \%)$ not concerned. Among them $175(96.2 \%)$ respondents were concerned about waste management, few o7 (3.8\%) respondents were not and majority of the respondents $111(61.0 \%)$ were not concerned about biomedical waste management and some respondents 71 (39\%) were concerned. Most of the 
respondents $164(90.1 \%)$ disposed sharp waste in red bin and some respondents 17 (8.9\%) were not disposed sharp waste in red bin.

Table 6. Distribution of the respondents by opinion regarding use of (PPE) personal protective equipment $(n=182)$.

\begin{tabular}{|l|l|l|}
\hline PPE use is important & Frequency & Percent \\
\hline Strongly agree & 85 & 46.7 \\
\hline Agree & 93 & 51.1 \\
\hline Disagree & 04 & 2.2 \\
\hline Total & 182 & \\
\hline
\end{tabular}

Table 6 shows that majority of the respondents agree 93 (51.1\%) about PPE use is important, 85 (46.7 \%) respondents strongly agree and few respondents $04(2.2 \%)$ were disagree.

Table 7. Distribution of the respondents by their practices about infection control $(\mathrm{n}=182)$.

\begin{tabular}{|l|l|l|}
\hline Practice assessment score & Frequency & Percent \\
\hline Poor & 11 & 6.0 \\
\hline Fair & 164 & 90.2 \\
\hline Good & 07 & 3.8 \\
\hline Total & $\mathbf{1 8 2}$ & $\mathbf{1 0 0 . 0}$ \\
\hline
\end{tabular}

The practice scores were categorized into Good (>80\%), Fair $(59-79 \%)$ and poor $(<59 \%)$.

The study revealed that most of the respondents $(90.2 \%)$ had fair practices, $(3.81 \%)$ had good practices and $(6.0 \%)$ had poor practices.

Table 8. Association between working experience and level of knowledge about infection control $(\mathrm{n}=182)$.

\begin{tabular}{|l|l|l|l|l|l|l|}
\hline \multirow{2}{*}{$\begin{array}{l}\text { Working experience } \\
\text { (in years) }\end{array}$} & \multicolumn{4}{|c|}{ Knowledge level } & Fisher's & \multirow{2}{*}{ E } \\
\cline { 2 - 5 } & Poor & Fair & Good & Total & \\
\hline $1-5$ & $1(11.1 \%)$ & $20(14.1 \%)$ & $3(9.7 \%)$ & $24(35 \%)$ & & \\
\hline $6-10$ & $0(0.0)$ & $11(84.6 \%)$ & $2(15.4 \%)$ & $13(100 \%)$ & \multirow{3}{*}{5.046} & \multirow{2}{*}{0.538} \\
\hline $10-15$ & $5(3.3 \%)$ & $42(77.8 \%)$ & $7(13.0 \%)$ & $54(100 \%)$ & \\
\hline 15 above & $3(3.3 \%)$ & $69(75.8 \%)$ & $19(20.9 \%)$ & $91(100 \%)$ & & \\
\hline Total & & & & 182 & & \\
\hline
\end{tabular}

Fishers exact test $=5.046, \mathrm{p}=0.538$

The study revealed that most of the nurses were working experience 15 and above years (20.9\%) had good knowledge, duration of working experience $10-15$ years, (77.8\%) had fair knowledge and working experience $1-5$ years $(11.1 \%)$ had poor knowledge. Significant statistical difference was found in knowledge level only in relation to working experience. Chi-square was not valid and Fishers exact done ( $\mathrm{p}=0.538)$.

\section{Conclusions and Recommendations}

Mainly the findings concluded that overall nurse's knowledge and practices were lack behind. Therefore to overcome the infection related burden nurses knowledge and practice should empower through regular interval of educational training program.

The study findings suggest the following recommendations:

- Education and training program using current evidence-based knowledge and practice would help improving the quality of nursing care.

- Regular monitoring and supervising of nurses.

- Availability of all facilities and personal protective equipment required for applying infection control standard precautions.

\section{Conflict of interest}

None to declare. 


\section{References}

Angelillo IF, A Mazziotta and G Nicotera, 1999. Nurses and hospital infection control: knowledge, attitudes and behavior of Italian operating theatre staff. J. Hosp. Infect., 42: 105-12.

Garba I, MD Farouq, GB Zaiyad, BT Abdulwasiu, A Salisu, SM Mohammad and AG Habib, 2015. Knowledge and practices of infection control among healthcare workers in a Tertiary Referral Center in North-Western Nigeria. Ann. Afr. Med., 15:34-40.

McBride A, 1994. Health promotion in hospitals: the attitudes, beliefs and practices of hospital nurses. J. Adv. Nurs., 20: 92-100.

Sax H, B Allegranzi, MN Chraiti, J Boyce, E Larson and D Pittet, 2009. The World Health Organization hand hygiene observation method. Am. J. Infect Control, 37: 827-34.

Vaidya A, 2016. 10 Best Strategies for Infection Prevention and Control. April 05, 2013. http://www.beckershospitalreview.com/quality/10-beststrategiesfor-infection-prevention-and-control.html.

Yokoe DS, LA Mermel, DJ Anderson, KM Arias, H Burstin and DP Calfee, 2008. A compendium of strategies to prevent healthcare-associated infections in acute care hospitals. Infect. Control Hosp. Epidemiol., 29:S1221. 